\title{
Groningen - its impact on European society
}

\author{
R.F.M. Lubbers
}

Chairman of the Mining Council, former Prime Minister of the Netherlands

In May 1973 I became Minister of Economic Affairs. That Ministry was and is responsible for energy. Those days "Groningen" was at the beginning of its lifetime. The first oil crisis of the second half of that year had an enormous impact on policies in The Netherlands and in Europe. In The Netherlands it was not only about overcoming the inconveniences of the oil crisis in the short term; it was also about structural consequences. One of them was the re-negotiation of profit sharing.

What had begun as a 70/30 split was changed already before I became minister (under Minister Langman) into an additional bracket, from a certain price level, of $85 / 15$. I negotiated an additional bracket of 95/05. Today, with the very low energy-prices this seems to be ages ago.

Another important change in policy was to go for a systematic to take advantage of Groningen for as long a time as possible. More concretely, the ambition became to have always enough gas for a generation to come (thirty years). In practical terms this limited sales contracts, more in particular export contracts. This policy had to be understood in connection with a policy of energy saving (as formulated in the first white paper on energy in 1974). This energy saving was a more general objective but it had its concrete consequences for the world of gas.

How to be selective in the use of the precious gas; and how to be as gas-saving as possible in those applications where, gas was the best alternative. If we compare the reality in the decades after this first white paper on energy (gas) with the ambitions in that white paper, the remarkable outcome is, that we did better than we thought those days (though the ambitions of those days were considered to be rather over-optimistic, too political, too rosy).

In connection with the ambition to have always enough gas for one Dutch generation, we made not only a plea to improve technology in order to take more benefit of Groningen, but also to develop the so-called "small fields", on the main land, in the North Sea and the "Waddenzee" (!).

When I left office as Prime Minister in August 1994, twenty-one years after I entered office as a Minister of Economic Affairs, the remaining reserves in terms of how many years still available for the Dutch population, the balance was: "still the same".

Therefore one might state, that the combination of policies in terms of conservation, improved technology and combining the potential of the "small fields" with Groningen was indeed successful.

I don't like to bore you with the whole history from 1973 till 1999, but it is an understatement to say that we are now living in a different world. Groningen had an enormous impact during decades on the energy supply in Western Europe; it still has.

At the very same time, the combination of conservation and improved technologies has produced an implosion of energy prices. Liberalization of markets think also about electricity generation - has brought a buyer's market. Because of the relevance of energy prices and the change in energy prices this is all good news for economic growth. At the very same time it is risky for stability.

How long will there be an abundance or are we once again wrong in our predictions?

And how to cope with climate change? Is it a serious problem and if so, what policies are needed to formulate the right answers?

And finally, what is the meaning of energy in general and gas in particular for Europe?

Some ten years ago I proposed the Energy Charter. Finally it developed into a rather modest Energy Charter Treaty. I make use of this opportunity to state, that it was a mistake not to go forward with the more ambitious concept of the Energy Charter. The ambition to leave it all to the market has been certainly one of the reasons of the disasters in the former Soviet Union. Chernobyl did not teach us a lesson.

Still, it's not too late.

Energy could still function as an instrument of integration and stability in the European continent. This 
is not only about energy, it is also about safety and the environment.

Groningen is now very mature; it is not at the end of its lifetime, but it is playing a more modest role in The Netherlands and in Europe; but still we can play a role in an integrated European approach.
But a conference such as this one can be used not only to tell the stories of the past, but also to formulate perspectives for the future. 